\title{
Age-Specific Differences in Asian Elephant Defecation, Dung Decay, Detection and Their Implication for Dung Count
}

Ashokkumar Mohanarangan ( $\sim$ vimalashok7@gmail.com )

Kerala Veterinary and Animal Sciences University https://orcid.org/0000-0003-3880-9991

Sakthivel Chinnaiyan

Sathyamangalam Tiger Reserve

Sudhakar Kaliyaperumal

Bombay Natural History Society

Swaminathan Shanmugavelu

Wildlife SOS

Ajay A Desai

WWF-India

\section{Research Article}

Keywords: Asian elephant, decay rate, defecation rate, dung count, growth curve, population estimation

Posted Date: August 16th, 2021

DOI: https://doi.org/10.21203/rs.3.rs-575344/v1

License: (c) (i) This work is licensed under a Creative Commons Attribution 4.0 International License. Read Full License 


\section{Abstract}

The various components of the dung count method of population estimation were evaluated such as defecation rate, decay rate, detection probability of dung and age-specific estimates of elephant density based on dung size. The defecation rate of elephants was determined in captive elephants of the Mudumalai elephant camp, Tamil Nadu, India. A total of 14 elephants in the dry season (Dec-Mar 2002) and 17 elephants in the wet season (Jun-Oct 2007) of different age-sex classes were observed for 42 days and 51 days by focal sampling methods and circumference of largest dung pile were measured to determine the growth curve. Total and age-specific elephant density based on dung circumference were estimated using indirect dung count method, 24 transect lines of $2 \sim 4 \mathrm{~km}$ resulting in a total of $125 \mathrm{~km}$ distance in Mudumalai Tiger Reserve. The dung decay rate was determined by marking fresh dung piles $(n=1628)$ every month with an average of $125 \pm 77$ dung piles/month from Jan 2007 to Feb 2008.

The mean defecation rate was $13.51 \pm 0.51(n=94)$ per day. The defecation rate varied across age-sex classes and seasons with a lower defecation rate for younger age classes. The dung circumference measurements showed similar growth curves to other Asian and African elephants. Dung size-based age classification significantly overestimates the adult age class, giving an estimate of $82 \%$ adults in the population against the true $48.5 \%$. Experimental analysis of detection of dung across perpendicular distance detection of larger and smaller dung size/age classes is equal at a visible distance and declined significantly for younger age/size class at the furthest distance. Decay rate varied significantly according to age classes and across seasons, with lower dung survival rates of younger age classes compared to adults. The minimum required sample size for the dung decay experiment was 250 . The age-specific estimate of elephant density based on the indirect dung count method revealed a precise estimate on density, both decay and defecation contribute less than $12 \%$ of the variance of the estimate. Age composition based on dung count is highly skewed towards adults, younger age class were low due to lower defecation and faster decay and lower probability of detection in the transect.

\section{Introduction}

Estimation of wildlife population with precision and accuracy is essential in wildlife management (Williams 2002). Population density and age structure are critical for the population biology of an organism. Estimating proper density and age composition is essential for assessing the impact of poaching, habitat management and population management of an endangered species (Riddle et al. 2010). Asian elephant (Elephas maximus) is listed as an endangered species due decline in the population over $50 \%$ in last three generations. India holds $60 \%$ of the Asian elephant population with an estimated population size of 29964 (Williams et al. 2020) and is being threatened by habitat degradation, conflict and poaching (Sukumar 1989; Riddle et al. 2010).

Both in Africa and Asia, elephant populations have been estimated using direct count (Dawson 1990; Varman and Sukumar 1995; Daniel et al. 2008; Goswami et al. 2019), aerial surveys (Norton-Griffiths 1978) and indirect count method (Merz 1986; Barnes et al. 1995; Oliver et al. 2009). The direct count 
method requires adequate spatial and temporal replication, less period of sampling to ensure population closure and an adequate number of detections to increase precision (Buckland et al. 2001; Jathanna et al. 2015). Dung count provides a more precise estimate than other methods because it records the accumulated presence of animals, variation among the transects is less (Barnes 2001) and more detection helps in better model fit in the distance sampling. Also, the cost involved in the survey, field equipment and field training requirement for volunteers is less. Further, the variance caused by defecation and decay rate is moderate (Barnes 2001). Both the defecation and dung survival rate were used as a denomination in the density estimation, which is exponentially related to dung density. when compared to the dung density the numerical values of both these variables are less and hence the variability within these factors causes less variance in the final estimate.

Population estimation based on dung count requires estimates of dung density, the dung production rate and the rate at which dung piles decay (Barnes and Jensen 1987; Dawson and Dekker 1992). But the defecation and decay rates were seldom estimated for specific sites and were borrowed from other studies that failed to fully capture their inherently high spatio-temporal and age-sex class variations. This can result in a substantially biased estimate of elephant density which has been highlighted in previous studies (Barnes et al. 1997). We have estimated defecation rate, dung decay rate in the South Indian population of elephants which can be used for estimating elephant density.

Apart from seasonal, habitat, regional and interannual variation in the defecation rate (Nchanji et al. 2008; Dawson 1990), we have tested age-specific variations in defecation that could potentially influence density estimates and age compositions based on the indirect dung count method. The elephant is longlived species and requires 10-15 years to reach sexual maturity and there is greater variation in the body size across age classes (Sukumar 1989). Hence we hypothesized that the defecation rate could vary across age classes and if so how does it affect the overall estimate, provided there is variation in the age composition in the population.

Similarly, studies on decay rate have shown habitat, seasonal and precipitation influence (Nchanji and Plumptre 2001). In the present study our second hypothesis was to test age-specific variation in the dung decay rate. We determined the minimum required sample size to estimate the dung decay rate based on the random selection of sub-samples.

Another important aspect of distance sampling is the detection probability. There are few studies on detection probability. Nichols et al. (2000) evaluated detection probability by the double observer. Estimating the factors that determine detection probability and incorporating them in the analysis is essential to increase the precision of the estimate. Hence our third hypothesis is, that larger dung piles of adult animals are easily visible for counting than younger animals dung piles that are small. In an experiment, we have evaluated dung piles that are available in the field and that are not being detected during the transect walk and also evaluated associated factors for the detection of dung piles.

It has long been recognized that age-structure data contain useful information for assessing the status and dynamics of wildlife populations (Caughley 1977; Williams 2002). Assigning age estimates can be 
difficult if the study organism is large and has a long lifespan. Birth registration and individual recognition are the only methods of assigning exact age, which may require a longer duration for surveying a larger fraction of the population (Moss 2001). In the indirect way to measure age composition, dung surveys also provide population demography based on dung size measurements (Jachmann and Bell 1984; Reilly 2002; Morrison et al. 2005). We have estimated the growth curve based on dung measurements for Asian elephants in South Indian. Further, the reliability of dung count method was not tested with a direct sighting or other methods. Our fourth hypothesize is to find out how the defecation, decay and detection probability of dung piles vary across age-sex classes that influence population estimate and age composition derived from dung measurements. The result of the study can be applied to other large herbivores and other mammal species with a longer life span.

In India in addition to the direct count method, the elephant population has been estimated based on indirect dung count method as project elephant population monitoring work through 'Synchronised Elephant Census' in the elephant range states (Bist 2003; Rangarajan et al. 2010), thus it is essential to evaluate parameters of dung count method to suggest proper estimation protocol.

\section{STUDY AREA}

Line transect surveys, age-sex composition and elephant dung decay rates were estimated in Mudumalai Tiger Reserve. The defecation rate of elephants was estimated in captive animals in elephant camps at Mudumalai in the Nilgiris district of Tamil Nadu ( $11^{\circ} 32^{\prime}$ and $11^{\circ} 42^{\prime} \mathrm{N}$ and $76^{\circ} 20^{\prime}$ and $76^{\circ} 45^{\prime} \mathrm{E}$ ). The tiger reserve extends over an area of $321 \mathrm{~km}^{2}$ and forms a part of the Nilgiri Biosphere Reserve (Fig. 1). The reserve is located in the Western Ghats, which is one of the 35 Biodiversity hotspots of the world (Myers et al. 2000). Altitude in the study area varies from $485 \mathrm{~m}$ to $1226 \mathrm{~m}$ above MSL with a general elevation of about 900 to $1000 \mathrm{~m}$. There are densely populated human settlements on its south-eastern boundary and also some smaller settlements inside the reserve. The study area has three major forest types namely Tropical Moist Deciduous (hereafter termed MDF), Tropical Dry Deciduous (DDF) and Southern Tropical Thorn forest (TF) (Champion and Seth, 1968). Rainfall varies from 600 mm in the eastern part to $2000 \mathrm{~mm}$ in the western part of the reserve.

\section{Methods}

\section{i. Defecation rate:}

The defecation rate of a species would be relatively constant at least in one habitat in a season (Barnes 1982; Dawson and Dekker 1992). The defecation rate of captive Asian elephants was gathered for different age-sex classes at Mudumalai. A total of 14 elephants in dry season (Dec-Mar 2002) and 17 elephants in wet season (Jun-Oct 2007) of different age-sex classes were observed for 42 days and 51 days respectively. Each elephant was followed for three consecutive days to get the defecation rate, thus resulting in the sampling effort of 339 and 456 hours of observation in dry and wet seasons respectively. 
Elephants were observed by the focal animal sampling method (Altmann 1974) during daytime for twelve hours from 6:00 hours to 18:00 hours. The number of defecations at night was determined by counting the number of dung piles at the site where the elephant was tethered (where cut fodder was given). Defecation for free-ranging captive elephants, which are released into forest area after evening concentrated rations (Cooked finger-millet, horse gram and coconut) with a long trailing chain to track them the next morning. During the study period elephants were left in separate areas and they left clear chain trails that could be easily followed and consequently, the number of defecations were counted. Elephants were given food supplements in the morning and evening and then released into the forest for free grazing, hence the major diet of these elephants is similar to that of the wild elephants (Ashokkumar 2002). The differences in the mean defecation rate across age-sex classes and seasons were tested by two-way analysis of variance.

\section{ii. Age composition}

The age-sex composition was determined based on direct sightings of elephants in the field. Every month selected routes were surveyed to ensure all habitats were sampled. Elephants were classified into various age-sex classes based on relative height and morphological characteristics (Mckay 1973; Daniel et al. 1987; Ashokkumar et al. 2010). Younger elephants ( $<15$ years) were classified by comparing their height to the oldest adult female in the group. Elephants were placed in broad age groups: Calves (<1year old), juvenile (1-5 year old), sub-adults (5-15 years) and adults ( $>15$ years). Dung size has been correlated to the size (height) of elephants and consequently to estimate age class (Reilly 2002, Morrions et al. 2005). To determine the age-class from dung size (circumference measured in the large end of dung bolus) of known age elephants in Mudumalai elephant camp and their measurements were used such as for adult with mean $47.7 \pm 4.95$ ( $\min 42$-max 64 ), sub-adults $35.1 \pm 2.76$ (31-42), Juveniles $26.4 \pm 2.49$ (22$30)$ and calves $18.6 \pm 2.59$ (13-21).

\section{iii. Growth functions and age keys}

The Von Bertalanffy growth equation was used to construct the growth models and is defined by growth parameters $L, K$ and $t_{0}$ and the length measurement $L$ (Von Bertalanffy 1938; Eqn 1 ) in this study was mean dung circumference.

$$
L_{t}=L(1-e)^{-k(t-t o)}
$$

This equation is characteristically asymptotic where $L$, is the theoretical maximum size of the length measurement, $\mathrm{K}$ (Brody growth coefficient) defines growth towards the maximum and $\mathrm{t}_{\mathrm{o}}$ is the theoretical age at 0 (Ebert 1999). Interpretation of growth parameters concerning elephant growth is discussed in Lee and Moss (1995), Reilly (2002) and Morrison et al. (2005). The Von Bertalanffy growth was fitted using statistical package R (R Development Core Team 2011). 


\section{iv. Dung density}

Dung density was determined using the indirect dung count method. A total of 24 transects of two to four kilometers resulting in a total of $125 \mathrm{~km}(56.5 \mathrm{~km}$ in dry season and $68.5 \mathrm{~km}$ in wet season) distance were walked (Fig.1). Transects were placed randomly in the study area to get adequate spatial coverage and proportional representation of three habitat types similar to an earlier study (Baskaran, Udhayan and Desai 2010). In the transect dung piles that are visible from the transect were counted, the perpendicular distance was measured using a measuring tape and the dungs were categorized into 'S-system' of Mike dung pile classification system (Hedges and Lawson 2006). All the dung piles encountered in the transects used to estimate dung density were measured. The largest circumference of an intact bolus in a dung pile was measured and categorized into age-class. If all the dung boli were not intact, the corresponding age class was denoted as unknown. The survey was completed within a month (July2007-wet and March 2008 - dry). This data compared to data on age classes observed for the population using a direct sighting method using a chi-squared test.

\section{v. Detection of dung piles}

Detection of various age-class and size class of dung at a different perpendicular distance was measured using experimental two belt transect in tropical dry deciduous forest with a length of two kilometers and width of $25 \mathrm{~m}$ on either side of the transect. Age class of dung piles was determined based on dung (intact boli circumference measured at the large end) measurements and size class of dung piles were categorized into large, medium and small based on natural log value of dung pile spread (length $\mathrm{x}$ width $\mathrm{x}$ height of dung).

Initially, dung piles that were visible from the transect were counted and marked with calcium carbonate powder to identify as detected. After completion of the transect count, the dung piles that were present within $25 \mathrm{~m}$ width on either side of transects that were not detected from transect were recorded as missed dung piles. This was done by placing a $100 \mathrm{~m}$ rope in the middle of the transect, and then the complete area was searched by four observers walking at a five-meter interval on one side of the transect. All missed dung piles in the transect were recorded with details of perpendicular distance, the extent of dung spread i.e. length and width of dung spread, presence of boli and dung boli circumference were measured. Then the other side of the transect was surveyed in the same method. It is hypothesized that the size/age class of the dung could influence the detection probability of dung along the transect. The proportion of dung piles detected at a different perpendicular distance was calculated by dividing the number of dung piles detected by the sum of the number of detected and non-detected dung piles at a particular distance.

Status of dung piles i.e., based on observed or missed were coded as 1 and 0 respectively. Individual dung measurement values such as perpendicular distance, age class (adult, sub-adult, juvenile and calf) of dung and size class (large, medium and small) and actual size (log value of length*width*height) were tested using binary logistic regression. 


\section{vi. Decay rate}

The elephant herds were located, tracked and fresh dung piles (less than six hours old) were marked in all three habitat types. Fresh dung piles were marked using numbered bamboo stakes every month an average of $125 \pm 77$ dung piles/month from Jan 2007 to Feb 2008 and monitored regularly till they disappear to estimate decay rate by prospective method (Dawson 1990). The variables such as geographic location, age class estimated based on dung circumference, grass composition, canopy cover and total length and width of dung spread were noted. Every month dung piles were marked in different habitats and revisited every 15 days to assess the status of dung piles. To estimate the decay rate (reciprocal of survival rate of dung piles) based on retrospective method dung piles were examined one day before the survey during dry and wet season.

A total of 1628 dung piles were marked and monitored over 13 months, but for decay rate analysis only the relevant months ( 6 months before survey) before the dung density transects were run, were used (Fig.1). The dung decay rate was estimated using the retrospective method (Laing et al. 2003). The dry season survey was started on 15 March 2008 and the wet season was on 20 July 2007. We checked all the dung piles, based on observation, decayed dung piles were denoted as 0 and those that were not decayed were denoted as 1 . The decay rate was estimated using logistic regression to find out any variation in decay rate acorss different seasons and across the age class of the elephant. Models based on maximum likelihood estimation of parameters were realized with the ' $\mathrm{glm}$ ' function family of the statistical package R using a modified code of CITES MIKE program (Hedges and Lawson 2006 and R Development Core Team 2011).

Variables in the analysis are the predictor variable age (day) and response variable state of dung piles that is presence/absence. This model allowed us to plot the logistic regression curves of dung age and determine the number of days needed for $50 \%$ of the dung to be considered decayed (Eq.1).

$$
P\left(Y=\frac{1}{x_{i}}\right)=\frac{e^{\alpha+\beta x+\alpha_{i}}}{1+e^{\alpha+\beta x+\alpha_{i}}}
$$

$a$ is the constant and $b$ co-efficient of time and $x$ representing the time (days). The mean dung decay and confidence interval were calculated by isolating the $\mathrm{x}$ factor from equation 1 using co-efficient $\mathrm{a}$ and b.

$$
X=\frac{\log \left(\frac{1}{Y}-1\right)+\alpha}{-\beta}
$$

\section{vii. Sample size influence on the decay rate}


The sample size influence on the decay rate was determined by random sub-sampling of dry season decay rate data $(n=1627)$. The sub-sampling procedure was carried out with $R$ software using 'for loop' procedure and the result was stored in a data frame to get the mean and standard error for each random sample. The sample size ranges from 10 to 500 and the procedure was repeated 50 times to determine the decay rate (standard error) in each sample size.

The Distance 7.2 software was used to estimate (Buckland et al. 2001; Thomas et al. 2010) overall and age-specific densities using appropriate defecation and decay rates. Sub-adult and calf defecation rates were available only for the wet season and juvenile defecation rates available only for the dry season. Hence defecation rates from other seasons were used to get the density estimate.

\section{Results}

\section{i. Defecation rate}

The overall defecation rate for 31 elephants observed over three days per elephant was $13.51 \pm 0.51$ $(\mathrm{n}=94)$ per day $(24 \mathrm{hrs})$. The mean defecation rate for adult males and females was $15.71 \pm 0.61$ and $11.05 \pm 0.92$ respectively. The defecation rate varied significantly between males and females $(F=2.54$; $d f=76 ; p<0.05$ ). The defecation rate of sub-adults (both sexes combined), juveniles (males) and calves were $10.56 \pm 0.90,10.41 \pm 0.87$ and $2 \pm 1.94$ respectively. Thus the defecation rate varied significantly among different age classes $(F=5.66 ; d f=76 ; p<0.05)$. The defecation rate varied among different seasons with a higher defecation rate during the dry season than wet season $(F=2.93 ; d f=76 ; p<0.05)$. The twoway interaction between the defecation rate of different age-sex classes and season was also significantly different $(F=7.68 ; d f=1 ; p<0.05)$ with a higher defecation rate observed during the dry season for both male and female (Table-1).

\section{ii. The relationship between age and defecation rate}

The relationship between the age of an elephant and the defecation rate was related to the power regression model. The defecation rate increased significantly with the age of the animal (Fig 2). The response variable elephant defecation is significantly proportional to the age of the animal raised to a power. The power regression equation model for a male elephant was $y=6.9 . x^{0.25}\left(R^{2}=0.31 ; F=26.6 ; d f=1\right.$; $p<0.00)$ and for a female, it was $y=3.498 . x^{0.34}\left(R^{2}=0.49 ; F=28.68 ; d f=1 ; p<0.00\right)$.

\section{iii. Growth curve}

Von Bertalanffy growth equation (VBGE) was fit between age (irrespective of sex) and dung circumference (Fig 3). For both sexes, dung circumference continues to grow from $13 \mathrm{~cm}$ to $42 \mathrm{~cm}$ from ages 0 to 15 years. Both sexes dung size continues to increase until the age of 30 years at which point the rate of increase markedly declines. Male elephant dung size continues to grow throughout its life. 
The derived growth parameters for male elephant and their confidence interval of the VBGE are Linf $=49.39 \pm 1.02$ (47.76 51.82); $\mathrm{t}_{0}=-2.62 \pm 1.99$ (-8.94 -0.10); $\mathrm{K}=0.12 \pm 0.026$ (0.07 0.17). The female elephant growth parameters are Linf $=42.87 \pm 2.24$ (39.84 - 49.32); $\mathrm{t}_{0}=-5.68 \pm 5.22(-25.18 \sim-0.78)$; $\mathrm{K}=0.10 \pm 0.06(0.03-0.32)$. A comparison of dung circumference at a specific age class showed female elephant dung size was 5 to $9 \mathrm{~cm}$ lower than males.

\section{iv. Age-sex composition based on dung count and direct sighting}

A total of 516 groups of elephants were sighted during the study period these all individuals in 479 groups were completely classified into different age-sex categories. Age structure data was compared with dung measurements. All the dung sighted on transects (for dung count-based population estimation) were measured and classed into different age categories. A total of 2488 dung piles were encountered and of these 1773 (79.3\%) dung piles had one or more boli of dung suitable for measuring the circumference. Dung size based age classification significantly overestimates the adult age class, giving an estimate of $82 \%$ adults in the population against an actual percentage of 48.5 as calculated using data from direct sighting $\left(c^{2}=6886 ; d f=4 ; p<0.00\right)$. The juvenile and calves were estimated as being $2.6 \%$ and $1 \%$ respectively by the dung size based estimate while the direct sighting based estimate was $14 \%$ and $20.9 \%$ respectively (Fig. 4 ).

\section{v. Detection of different dung size classes}

The proportion of detection of different size classes (spread of dung bolus length and width, irrespective of age class) of dung varied at a different perpendicular distance. The detection of dung within visible range $(10 \mathrm{~m})$ was $0.99,0.92$ and 0.82 for large, medium and small dung (Fig 5). Detection declined further distance away from the transect. Mean detection after $10 \mathrm{~m}$ was 0.71 for larger dung, and it was 0.55 and 0.13 for medium and small dung piles respectively. Thus, the proportion of dung detected varied across different size classes of dung. At the furthest distance, detection is maximum for larger dung piles. Further number of dung piles recorded $>10 \mathrm{~m}$ perpendicular distance was constituted $23 \%$ $(n=115)$ of overall observations.

Binary logistic regression indicated there is a significant difference in the detection across various perpendicular distance and size classes. Among the three categories detection of large and small dung piles varied significantly $(z=-2.73 ; p=0.006)$.

\section{vi. Detection of different age-class of dung}

Detection of different age-class dung piles at different perpendicular distances from the transect varied. Within the visible range of perpendicular distance of $10 \mathrm{~m}$, the mean proportion of detection of the adult, sub-adult, juvenile and calf dung were $0.98,0.91,0.88$ and 0.58 respectively (Fig 6). At the furthest distance from the transect line (beyond $10 \mathrm{~m}$ ) detection of adult, sub-adult, juvenile and calf was 0.74 , 
$0.43,0.33$ and 0.17 respectively. Thus the detection of adult and calf dung within visible range is similar. At the furthest distance $(>10 \mathrm{~m})$ from the transect line, detection of a different age class of dung varied with higher detection of adult dung piles than juvenile and calf dung piles. However, multiple logistic regression based on detection based on age categories did not show any significant difference.

\section{vii. Differential decay rate}

The mean survival rate of dung piles ranges from 22 to 172 and it was higher in the wet season (133.68) than in the dry season (116.83). Among the age class survival rates were the highest for adult animals (137) and lowest for calves (56) in the wet season. The adult elephant's dung decay rate (reciprocal of dung survival) was used as a reference category to find differences with other age classes. The results of multiple logistic regressions indicated that in the dry season decay rate varied significantly only between adults and calves $(z=-4.055 ; p=0.00)$. In the wet season, decay rate varied significantly among adults, sub-adults and calves (Table-2).

\section{viii. Decay rate influenced by sample size}

The dung decay rates across different sample sizes were tested using a random selection of samples ranging from 10 to 500 . The percent coefficient of variation was higher $(24 \%)$ for a small sample size $(n=10)$ and declined with increasing sample size. To get $<5 \%$ co-efficient of variations, the required sample size was $>250$ dung samples. If more than 50 dung samples were marked across different months, then this would produce $<10 \% \mathrm{CV}$. (Fig 7).

\section{ix. Elephant density}

The age-specific estimate of dung density revealed a higher density of adult animals, followed by subadult, juvenile and calves (Table-3). In the total estimate, effective strip width was low during the wet season $(1.81 \pm 0.08 \mathrm{~m})$ than during the dry season $(4.14 \pm 0.17 \mathrm{~m})$. Estimated elephant density was marginally higher in the wet season (2.55) than in the dry season (2.02). The percent contribution of variance to the estimate by defecation rate and decay rate was $10.4-11.6 \%$ and $0.5-0.6 \%$ in wet and dry seasons respectively. Encounter rate and the probability of detection of dung contribute $80 \%$ and $6 \%$ irrespective of the season.

\section{Discussion}

\section{i. Defecation rate}

The defecation rate varied significantly between adult males and females, across age classes and seasons. Significantly, higher defecation rates were observed during the dry season in both sexes. 
The reported defecation rates in this study are slightly lower than those reported for the wet season by Dawson (1990) in the study area. The earlier study reported defecation rates of 13.3 (early monsoon), 14.6 (monsoon) and 15.9 (post-monsoon) for different periods of the wet season. For the dry season, the study had reported a defecation rate of 9.3 per day. Studies by Reilly (2002) in Way Kambas NP in Indonesia gave different rates for the dry season in two different years, 11.83 (dry season 1994) and 13.04 (dry season 1997). The wet season defecation rate was given as 17.93 . What is apparent is that there are differences between years for the same season as well as the difference between seasons as shown by these earlier studies. Similarly in Africa, a study by Theuerkauf and Ellenberg (2000) shows some differences between wet (16.6) and dry (18.1) season defecation rates. Seasonal variation in the defecation might be due to variations in the protein, fiber and moisture content of food (Guy 1975; Barnes 1982; Dawson 1990). Tchamba (1992) reported a defecation rate of 19.77 (combined wet and dry season) for elephants in Cameroon and although this was a wet evergreen forest habitat like the study area of Theuerkauf and Ellenberg (2000) (in Ivory Coast) the rates of defecation differed. So, different sites are likely to have different rates based on the local conditions and diet of the elephants. The generalization of elephant defecation rate based on rainfall model (Theuerkauf and Gula 2010) has to be dealt with caution since there is variation in the defecation rates within a particular season and age class.

The present study brings into focus another aspect, namely differences in defecation rates between different age and sex classes. The population with higher composition adult age classes, the defecation rate may not influence much on the density. Since adult and sub-adult having similar defecation rates. Whereas a population with a lot of younger animals, the use of adult defecation rates could potentially underestimate the density. Hence, it is essential to study age composition based on the direct method and use an age-specific defecation rate to estimate density.

The defecation rate significantly increased with the age of the elephant. The power regression equation model for the male and female elephants was $y=6.9 . x^{0.25}$ and 3.498. $x^{0.34}$. Body size, sexual dimorphism and the quantity of food consumed varied between male and female and across age classes that could result in differences in defecation rate. Further higher defecation rate enables to encounter more number of dung piles available to count thus reduces variation in the spatial samples and better model fit between perpendicular distance and dung detection and thus precise estimation of dung density.

\section{ii. Growth curve}

In this study, the growth models were not used to predict the actual age of an animal from dung measurements but help to determine the population age structure. The growth patterns of dung piles were similar to other populations of Asian and African elephants (Sukumar et al. 1988; Lee and Moss 1995; Reilly 2002). The curve depicting growth in an average Asian elephant suggests that they continue to grow during adulthood. There are limitations in predicting ages for elephants with length measurements greater than the theoretical maximum $\left(L_{a}\right)$ and as length approaches this asymptotic limit 
the growth equations become increasingly sensitive to a small increase in size. Hence, the growth models are most sensitive at predicting ages up to 30 years. Hence, we grouped all the individuals above 15 years as adults. Further, it was (Jachmann and Bell 1984) reported that there were regional variations in the growth curve of elephant populations. Thus, this growth curve can be used to estimate age class based on dung measurements in the Southern Indian Asian elephant population.

\section{iii. The proportion of dung detected across perpendicular distance}

Detection of different size classes of dung piles and age classes of elephants varied within visible range and further away from the transect. There was a significant difference in the detection of dung piles at farther distances, for example after $10 \mathrm{~m}$ from the transect line, the detection of larger dung pile was 0.71 and it was 0.13 for smaller dung piles. Detection probability of different cluster sizes of animal sightings has been incorporated in distance sampling to estimate size-bias in detection probability and correct this error to get the final estimate (Buckland et al. 2001). We have used dung size and age classes in the distance program to find out size bias detection in the dung count. But, there was no significant difference in size bias detection based on the entire data set. Then we have left truncated our data for the visible distance of $10 \mathrm{~m}$ that resulted in the size bias in the detection based on dung size. It could be possibly due to the assumption in distance sampling that the probability of detection of a different group size of animals/size class of dung is regressed with a perpendicular distance parameter. However, the assumption may not be valid, hence detection of larger and smaller clusters/group size/dung size classes is equal at a visible distance. Further inclusion of these data values in the linear regression analysis with or without transformation of cluster size could result in heteroscedasticity of data nearvisible distances. It is inferred that the probability of sighting of large and small dung is equal at a visible distance and size-bias in detection occurs at the furthest distance. Hence, it is suggested that in the distance sampling method it is necessary to find out the visible distance range of species interest and incorporate in analysis to produce size-bias regression rather than using the entire dataset. These modifications can also be incorporated in the distance software program to increase the accuracy of the estimate.

Detection of dung/species depends on factors such as the observer experience on a similar survey, size of the object/cluster size and perpendicular distance. The observer efficiency in the detection of dung or counting animals can be increased by experience. The observer bias indirect count method can be determined by a double observer in the transect (Nichols et al. 2000) and was tested in aerial counts of elephants in Africa (Schlossberg, Chase and Griffin 2016). Secondly, in the dung count, it is important to measure the dung size class/age class, since there is variation in the detection probability of different age classes of dung. Finally, the use of equipment such as measuring tape and compass can increase the precision of measurements of perpendicular distance.

\section{iv. Differential decay rate}


The decay rate estimated using the retrospective method varied significantly among seasons and age classes. The decay rate (reciprocal of survival of dung piles) is considered a crucial factor in determining elephant density because of numerically higher value (Mean dung survival range 111-173) than defecation rate and has a greater influence on the final estimate. Dung decay rates tend to vary with habitat, dung beetle activity, precipitation and canopy cover (Nchanji and Plumptre 2001). Daniel et al. (2008) reported habitat, seasonal, monthly and microhabitat variation in the dung survival rate in the study area with a higher survival rate in the open swamps ( $121 \pm 11$ days) and by the roadside $(119.9 \pm 3.8$ days). Seasonal and within-season variation in the dung decay were reported in African elephants (Nchanji and Plumptre 2001). Though habitat, seasonal and monthly variation in decay rate had been reported in elephants (Barnes et al. 2006; Oliver et al. 2009) age-specific decay rate has not been reported earlier. Dung decay rate varied according to season and age-sex class.

An important aspect of the decay experiment is how many samples were needed to estimate the decay rate. In the present study, the sub-sampling procedure based on different samples size to determine the decay rate indicated more than 250 dung samples were required to estimate the decay rate with less than $5 \%$ coefficient of variation. Hiby and Lovell (1991) recommended sample size of 100 dung piles to be monitored to determine the decay rate. Since reciprocal of dung survival is used as decay rate which is the denominator of dung density has the primary influence on density estimate, but due to exponential decay curve per unit change of dung survival has a fractional change in the density.

\section{v. Age-composition based on dung count}

A significantly higher proportion of adults (82\%) estimated through the dung count than the direct estimate (48.5\%) could be due to a higher defecation rate of adult animals (12-17) than of other age classes. Dung based estimate for juveniles and calves was $2.6 \%$ and $1 \%$, which is significantly lower than the direct estimate of $14 \%$ and $20.9 \%$ respectively. This could be due to differences in three factors such as defecation rate, the differential decay rate and detection probability of dung piles. Adult elephants produce significantly more dung piles (14/day) than calves (2/day). The dung pile decay rate was significantly low for young animals than adults at least in a particular season. Further probability of detection of dung for the calf was lower than in adults. Hence, age-composition based on dung count tends to underestimate juveniles and calves in the population due to differences in the defecation, decay rate and detection probability of different age-class dung piles. Oliver et al. (2009) reported a few newborns in African elephants in the data extrapolated from the dung measurements and this number was correlated with the population structure of elephants in Maputo Elephant Reserve. They have used defecation rate derived from other studies (Coe 1972), detection of dung piles based on only observed dung piles. Similarly, the comparison of age composition based on direct count and dung measurements in the Sumatran elephant was significantly different with a lower proportion of adults in the population. She speculated that these differences might be due to a lower number of direct sightings in the analysis (Reilly 2002). Though the authors in the previous studies reported differences in the demography based on dung count, the exact reason for the difference could be due to these three factors. Thus, estimation 
of age structure based on dung count should be dealt with caution, since defecation, decay rate and detection varies across age class.

\section{vi. Elephant density}

Estimated elephant density was marginally higher in the wet season $(2.55 \pm 0.45)$ than in the dry season (2.02 \pm 0.33$)$. The differences in wet and dry season were due to local seasonal movements of elephants in the study area. Mudumalai TR is part of a larger elephant range that includes elephant reserves 7 and 8 and covers an area of over $1500 \mathrm{~km}^{2}$. Elephants from Mudumalai have been shown to have large home ranges over $600 \mathrm{~km}^{2}$ (Baskaran et al. 1995), which is more than twice the size of the study area. Thus, the population estimate should be considered as an average number of elephants using the study area during the sampling period.

The present population estimate is higher than the earlier estimate of $1 / \mathrm{km}^{2}$ (Daniel et al. 1987) and marginally higher than the earlier estimate (2000) by direct count method $2.39 \pm 0.72 / \mathrm{km}^{2}$ (Baskaran, Udhayan and Desai 2010). The estimated density is lower than the direct count method conducted at the same period in the dry season (3.27 \pm 1.39$)$ in the study area (Daniel et al. 2008). Although there were differences in the estimate based on the two methods, the precision of the estimate from dung count is greater than that of the direct count method. The estimated elephant density and precision were similar or higher than the estimate from the direct count method $(2.24 ; 1.41-3.56)$ in Nagarahole National park in South India (Jathanna et al. 2015). Direct sampling requires several temporal replications to increase the number of sightings (4-6 replications per transect; Jathanna et al. 2015) and further invasion of exotic species in the forest areas hampers visibility in the transect that could in turn influence the detection of animals and raise the possibility of an encounter with an elephant in at a close distance. In the dung count the effort need to estimate dung density is less one-time survey is sufficient. Further to estimate decay rate forest-field staffs can mark the dung piles prior to the survey and the status of the dung piles can be enumerated at the time of the survey.

In the present study, we propose an age-specific density estimation based on the dung count method. This estimated proportion of adults 69.4 (in wet and dry season) was higher than the estimate derived from the direct sighting of elephants (48.47\%). Thus, the adult elephant population was significantly overestimated in the dung count even age-composition based on dung count also revealed a similar percent. The estimated sub-adult proportion (19.9 and $21.7 \%$ in wet and dry season) in the population was marginally higher than the direct sighting estimates (16.6\%). The proportion of juveniles in the estimate was low (2-3\%) than the actual population (14\%). Though juveniles had a similar defecation rate of sub-adults, dung density was low in the transect. The decay rate of the juvenile was higher (wet season) and detection of dung piles in the transect within visible range $(10 \mathrm{~m})$ was lower than adult dung piles. Similarly, the estimated percent of calves ( 8.6 and $5.9 \%$ in dry and wet season respectively) was lower than the estimate obtained from the direct count method (20.9\%). Significantly lower defecation 
rate, rapid decay and lower detection probability could have resulted in a lower proportion of younger age class in the density estimate.

The dung count method estimates density with reasonable accuracy if the following conditions are met such as 1 . Estimation of dung decay rate prior ( 4 to 5 months) to the survey with $>250$ samples marked across different vegetation; 2 . Transect with adequate spatial replicate; 3 . Random placement of transect; 4. Use of measuring tape to enumerate perpendicular distance and measuring dung boli to estimate age composition; 5. Determination of defecation rate from the captive elephant population in the regional locations. Further combination of direct and indirect methods can be used to estimate elephant population and age composition. The comparison of dung count and fecal DNA based capture-recapture estimation (Gray et al. 2014) can be tested in the elephant ranges. DNA based methods provide further insight into population structure and genetic relatedness.

\section{MANAGEMENT IMPLICATIONS}

The defecation rate significantly increased with the age of the elephant and varied between adult males and females, across age classes and seasons. Age structure estimated from dung measurement revealed a lower percent of younger animals. Hence elephant population demographic assessment based on dung count should be cautiously interpreted due to variation in defecation and dung detection. Experimental study on dung count indicated that within visible distance, size-bias does not exist and inclusion of this data in regression increases heteroscedasticity in the model results in failure to detect size bias in detection probability or haphazard regression model. Further options to include multiple age-specific defecation and decay rate in the model in the Distance software could help in analysis.

\section{Declarations}

NA

Funding: US fish and Wildlife Service Ref No. AAA No. 98210-6-G113

Conflicts of interest/competing interest: We do not have any conflict of interest

Availability of data and material: The data were presented in the manuscript and ready to submit raw data if needed

Code availability: NA

Authors' contributions: MA: Involved in data collection, developed theory, performed computation and prepared manuscript. SC and SK Assisted in the field sample collection and preparation of the manuscript. SS and AAD Supervised the work and revision of the manuscript. All authors discussed the results and contributed to the final manuscript

\section{Acknowledgements}


We thank the TNFD, Tamil Nadu for permitting us to undertake this study. We thank the US Fish and Wildlife Service for providing funding support (AAA No. 98210-6-G113). We thank the former Director and Honorary Secretary of BNHS.

\section{References}

Altmann J (1974) Observational study of behaviour: Sampling methods. Behav 49:227-267.

Ashokkumar M (2002) Studies on Asian elephant (Elephas maximus) in captivity at Mudumalai Wildlife Sanctuary with special reference to its dung size as a parameter to estimate the age structure. M.Sc., Dissertation, A.V.C. College, Mannampandal, Tamil Nadu, India.

Ashokkumar M, Nagarajan R, Desai AA (2010) Group size and age-sex composition of Asian elephant and Gaur in Mudumalai Tiger Reserve, Southern India. Gajah 32:27-34.

Barnes RFW (1982) Elephant feeding Behaviour in Ruaha National Park, Tanzania. Afr J Ecol 20:23-136.

Barnes RFW (2001) How reliable are dung counts for estimating elephant numbers?. Afr J Ecol 39:1-9.

Barnes RFW, Asamoah-Boateng B, Naada Majam J, Agyei-Ohemeng J (1997) Rainfall and the population dynamics of elephant dung piles in the forests of southern Ghana. Afr J Ecol 35:39-52.

Barnes RFW, Jensen KL (1987) How to count elephants in forest, IUCN (Int. Union Conserv. Nat. Nat. Resour.), African Elephant Rhino Spec. Group Technical Bulletin 1:1-6.

Barnes RFW, Blom A, Alers MPT, Barnes KL (1995) An estimate of the numbers of forest elephants in Gabon. J Trop Ecol 11:27-37.

Barnes RFW, John Naada Majam JN, Asamoah-Boateng B, Agyei-Ohemeng J (2006) The survival of elephant dung piles in relation to forest canopy and slope in southern Ghana. Pachyderm 41:37-43.

Baskaran N, Balasubramanian M, Swaminathan S, Desai AA (1995) Home range of elephants in the Nilgiri Biosphere Reserve. In: Daniel JC, Datye HS (eds) A Week with Elephants. Bombay Natural History Society, Bombay. pp 296-313

Baskaran N, Udhayan A, Desai AA (2010) Status of the Asian elephant population in Mudumalai Wildlife Sanctuary, Southern India. Gajah 32:6-13.

Bist S (2003) An overview of the methods for enumeration of wild elephants in India. Gajah 22:67-70.

Buckland ST, Andersen DR, Burnham KP, Laake JL, Borchers DL, Thomas L (2001) Introduction to Distance Sampling: Estimating Abundance of Biological Populations. Oxford University Press Inc., New York, USA. 
Caughley G (1977) Analysis of Vertebrate Populations. John Wiley and Sons, London, UK.

Champion HG, Seth SK (1968) A Revised Survey of the Forest Types of India. Government of India, New Delhi.

Coe MJ (1972) Defecation by African elephants (Loxodonta africana Africana (Blumenbach). East Afr Wildl J 10:165-174.

Daniel JC, Desai AA, Sivaganesan N, Ramesh KS (1987) The study of some endangered species of wildlife and their habitats, The Asian Elephant Report, October 1985 to September 1987, Bombay Natural History Society, Bombay.

Daniel JC, Desai AA, Ashokumar M, Sakthivel C (2008) Evaluating population enumeration methods and human-elephant conflict mitigation methods in Mudumalai Tiger Reserve, Tamil Nadu, India, Final Report, Bombay Natural History Society, Mumbai.

Dawson S, Dekker AJFM (1992) Counting Asian Elephants in Forests. A Techniques Manual. RAPA Publication 1992/11. RAPA and FAO, Bangkok.

Dawson S (1990) A model to estimate the density of Asian elephants (Elephas maximus) in forest habitats. MSc thesis, University of Oxford, Oxford, UK.

Ebert TA (1999) Plants and animals population: Methods in demography, Academic Press, San Diego

Goswami VR, Yadava MK, Vasudev D et al. (2019) Towards a reliable assessment of Asian elephant population parameters: the application of photographic spatial capture-recapture sampling in a priority floodplain ecosystem. Sci Rep 9:8578 https://doi.org/10.1038/s41598-019-44795-y

Gray TNE, Vidya TNC, Potdar S, Bharti DK, Sovanna P (2014) Population size estimation of an Asian elephant population in eastern Cambodia through non-invasive mark-recapture sampling. Consev Gen 15:803-810.

Guy PR (1975) The daily food intake of the African elephant Loxodonta Africana Blumenbach in Rhodesia. Arnoldia 7:1-8.

Hedges S, Lawson D (2006) Dung Survey Standards for the MIKE Programme. CITES MIKE Programme, Central Coordinating Unit, Nairobi, Kenya.

Hiby L, Lovell P (1991) DUNGSURV - a program for estimating elephant density from dung density without assuming steady state. In: Ramakrishnan U, Santosh J, Sukumar R (Eds) Censusing Elephants in Forests: Proceedings of an International Workshop. Asian Elephant Conservation Centre, Bangalore, India, pp 73-80. 
Jachmann H, Bell RHV (1984) The use of elephant droppings in assessing numbers, occupancy and age structure: a refinement of the method. Afr J Ecol 22:127-141.

Jathanna D, Karanth KU, Samba Kumar N, Goswami VR, Vasudev D, Karanth KK (2015) Reliable monitoring of elephant populations in the forests of India: Analytical and practical considerations, Biol Conserv 187:212-220.

Laing SE, Buckland ST, Burn RW, Lambie D, Amphlett A (2003) Dung and nest surveys: estimating decay rates. J Appl Ecol 40:1102-1111.

Lee PC, Moss CJ (1995) Statural growth in the African elephant (Loxodonta africana), J Zool 236:29-41. Mckay GM (1973) Behaviour and ecology of the Asiatic elephant in Southeastern Ceylon, Smithsonian Contribution to Zoology, Vol.125, Smithsonian Institution, Washington, DC.

Merz G (1986) Counting elephants (Loxodonta africana cyclotis) in tropical rain forests with particular reference to the Tai National Park, Ivory Coast. Afr J Ecol 24:61-68.

Morrison TA, Chiyo PI, Moss CJ, Alberts SC (2005) Measures of dung bolus size for known-age African elephants (Loxodonta africana): implications for age estimation. J Zool 266:89-94.

Moss CJ (2001) The demography of an African elephant (Loxodonta africana) population in Amboseli, Kenya, J Zool 255:145-156.

Myers N, Mittermeier RA, Mittermeier CG, da Fonseca GA, Kent J (2000) Biodiversity hotspots for conservation priorities. Nature 403:853-858.

Nchanji AC, Forboseh PF, Powell JA (2008) Estimating the defecation rate of the African forest elephant (Loxodonta cyclotis) in Banyang-Mbo Wildlife Sanctuary, South-Western Cameroon. Afr J Ecol 46:55-59.

Nchanji AC, Plumptre AJ (2001) Seasonality in elephant dung decay and implications for censusing and population monitoring in South-Western Cameroon. Afr J Ecol 39:24-32.

Nichols JD, Hines JE, Sauer JR, Fallon FW, Fallon JE, Heglund J (2000) A double observer approach for estimating detection probability and abundance from point counts. The Auk 117(2):393-408.

Norton-Griffiths M (1978) Counting Animals, Handbooks on techniques currently used in African wildlife ecology. No.1, African Wildlife Leadership Foundation.

Oliver PI, Ferreira SM, van Aarde RJ (2009) Dung survey bias and elephant population estimates in southern Mozambique. Afr J Ecol 47:202-213.

Rangarajan M, Desai AA, Sukumar R, Easa PS, Menon V, Vincent S, Ganguly S, Talukdar BK, Singh B, Mudappa D, Chowdhary S, Prasad AN (2010) Gajah: securing the future for elephants in India, Report of the Elephant Task Force, Ministry of Environment and Forests, New Delhi, India. 
Reilly J (2002) Growth in the Sumatran elephant (Elephas maximus sumatranus) and age estimation based on dung diameter. J Zool 258:205-213.

Riddle HS, Schulte BA, Desai AA, Meer LVD (2010) Elephants - a conservation overview. JoTT 2:653-661.

Schlossberg S, Chase MJ, Griffin CR (2016) Testing the accuracy of aerial surveys for large mammals: An experiment with African Savanna Elephants (Loxodonta africana), Plos one,

DOI:10.1371/journal.pone.0164904.

Sukumar R (1989) The Asian elephant: ecology and management, Cambridge University Press, USA, $251 \mathrm{p}$.

Sukumar R, Joshi NV, Krishnamurthy V (1988) Growth in the Asian elephant, Proc Indian Acad Sci (Anim Sci) $97: 561-571$.

Tchamba MN (1992) Defecation by the African forest elephant (Loxodonta africana cyclotis) in the Santchou reserve, Cameroon. Mammalia 56:155-158.

Theuerkauf J, Ellenberg H (2000) Movements and defecation of forest elephants in the moist semideciduous Bossematie Forest Reserve, Ivory Coast. Afr J Ecol (38):258-261.

Theuerkauf J, Gula R (2010) Towards standardization of population estimates: defecation rates of elephant should be assessed using a rainfall model. Annal Zool Fenn 47:398-402.

Thomas L, Buckland ST, Rexstad EA Laake JL, Strindberg S, Hedley SL, Bishop JRB, Marques TA, Burnham KP (2010) Distance software: design and analysis of distance sampling surveys for estimating population size. J Appl Ecol 47:5-14.

Varman KS, Sukumar R (1995) The line transect method for estimating densities of large mammals in a tropical deciduous forest: An evaluation of models and field experiments, J Biosci 20(2):273-287.

Von Bertalanffy L (1938) A quantitative theory of organic growth. Hum Biol 10:181-213.

Williams BK, Nichols JD, Conroy MJ (2002) Analysis and management of animal populations. Academic Press.

Williams C, Tiwari SK, Goswami VR, de Silva S, et al. 2020. Elephas maximus. The IUCN Red List of Threatened Species 2020: e.T7140A45818198. https://dx.doi.org/10.2305/IUCN.UK.20203.RLTS.T7140A45818198.en

\section{Tables}

Table-1: Defecation rate of the captive Asian elephant in different season and across agesex classes (Dry season $n=14$; wet season $n=17$ ) in Mudumalai Tiger Reserve 


\begin{tabular}{|l|r|c|c|c|c|}
\hline \multirow{2}{*}{ Age class } & \multicolumn{2}{|c|}{ Wet (n=339 hours) } & \multicolumn{2}{c|}{ Dry (n=456 hours) } & ANOVA \\
\cline { 2 - 6 } & Mean $\mathbf{~ S E ~}$ & 95\% CI of Mean & Mean + SE & 95\% CI of Mean & \\
\hline Adults & $13.68 \pm 0.73$ & $12.23-15.14$ & $16.04 \pm 0.63$ & $14.79-17.29$ & $\mathrm{~F}=2.93 ;$ \\
Adult male & $15.68 \pm 0.77$ & $14.15-17.21$ & $17.83 \pm 0.70$ & $16.43-19.22$ & $\mathrm{df}=76 ;$ \\
Adult female & $9.89 \pm 1.06$ & $7.78-12.00$ & $13.48 \pm 0.84$ & $11.81-15.15$ & $\mathrm{p}<0.05$ \\
Sub-adults & $10.56 \pm 0.90$ & $8.78-12.35$ & - & - & \\
Juveniles & - & - & $10.41 \pm 1.12$ & $8.19-12.64$ & \\
Calf & $2.0 \pm 0.01$ & - & - & - \\
Overall (n=94) & $11.97 \pm 0.68$ & $10.59-13.35$ & $14.99 \pm 0.68$ & $13.60-16.36$ & \\
\hline ANOVA & \multicolumn{7}{|c|}{$\mathrm{F}=5.66 ; \mathrm{df}=76 ; \mathrm{p}<0.05$} & \\
\hline
\end{tabular}

SE- Standard Error; CI- Confidence interval

Table-2: Mean survival rate of dung piles of elephant estimated from logistic regression in different seasons in Mudumalai Tiger Reserve

\begin{tabular}{|c|c|c|c|c|c|}
\hline \multirow[t]{2}{*}{ Age-class } & \multirow[t]{2}{*}{ Mean survival rate of dung $\pm \mathrm{SE}$} & \multirow[t]{2}{*}{ df } & \multicolumn{2}{|c|}{$95 \%$ CI of Mean } & \multirow{2}{*}{$\begin{array}{c}\text { Logistic regression } \\
\text { p values }\end{array}$} \\
\hline & & & Lower & Upper & \\
\hline \multicolumn{6}{|l|}{$\overline{D R Y}$} \\
\hline Adults $\underline{o}$ & $118.06 \pm 2.889$ & 1103 & 112.4 & 123.7 & $\underline{\mathbf{o}}$ \\
\hline Sub-adults & $106.93 \pm 4.49$ & 300 & 98.1 & 115.7 & $\mathrm{z}=0.824 ; \mathrm{p}=0.410$ \\
\hline Juveniles & $123.15 \pm 10.519$ & 101 & 102.5 & 143.8 & $\mathrm{z}=0.749 ; \mathrm{p}=0.454$ \\
\hline Calf & $118.41 \pm 13.793$ & 102 & 91.4 & 145.4 & $\mathrm{z}=-4.055 ; \mathrm{p}=0.000^{*}$ \\
\hline Total & $116.83 \pm 2.439$ & 1627 & 112.0 & 121.6 & \\
\hline \multicolumn{6}{|l|}{ WET } \\
\hline Adults $\underline{\mathbf{o}}$ & $137.11 \pm 18.021$ & 410 & 101.8 & 172.4 & $\underline{\mathbf{0}}$ \\
\hline Sub-adults & $93.63 \pm 17.786$ & 103 & 58.8 & 128.5 & $\mathrm{z}=-2.235 ; \mathrm{p}=0.025^{*}$ \\
\hline Juveniles & $58.65 \pm 18.517$ & 29 & 22.4 & 94.9 & $\mathrm{z}=0.003 ; \mathrm{p}=0.997$ \\
\hline Calf & $56.15 \pm 14.595$ & 70 & 27.5 & 84.8 & $\mathrm{z}=-2.331 ; \mathrm{p}=0.0197^{*}$ \\
\hline Total & $133.68 \pm 15.756$ & 615 & 102.8 & 164.6 & \\
\hline
\end{tabular}

o - Reference category; *-statistically significant

Table-3: Age-specific estimate of elephant dung density, decay rate and elephant density in Mudumalai Tiger Reserve 


\begin{tabular}{|c|c|c|c|c|c|c|c|}
\hline Seasons & $\begin{array}{l}\text { Age- } \\
\text { class }\end{array}$ & Dung density & $\begin{array}{c}\text { Decay rate } \\
\text { /day }\end{array}$ & $\begin{array}{c}\text { Elephant density } \pm \\
\text { SE }\end{array}$ & $\begin{array}{c}95 \% \text { CI of } \\
\text { mean }\end{array}$ & $\begin{array}{l}\text { CV } \\
(\%)\end{array}$ & $\mathbf{n}$ \\
\hline \multirow{5}{*}{$\begin{array}{c}\text { Wet } \\
(68.5 \\
\mathrm{km})\end{array}$} & Adult & $\begin{array}{l}3866 \pm \\
620.95\end{array}$ & $0.0073 \pm 0.003$ & $2.06 \pm 0.359$ & $1.45-2.93$ & 17.4 & 872 \\
\hline & $\begin{array}{l}\text { Sub- } \\
\text { adult }\end{array}$ & $579.6 \pm 200.4$ & $0.0107 \pm 0.006$ & $0.59 \pm 0.212$ & $0.29-1.18$ & 36.1 & 106 \\
\hline & Juvenile* & $36.62 \pm 20.23$ & $0.0171 \pm 0.010$ & $0.06 \pm 0.033$ & $0.02-0.17$ & 55.6 & 12 \\
\hline & Calf & $29.71 \pm 16.68$ & $0.0178 \pm 0.008$ & $0.26 \pm 0.149$ & $0.09-0.78$ & 72.7 & 7 \\
\hline & Total & $\begin{array}{r}4073.9 \pm \\
675.84 \\
\end{array}$ & $\begin{array}{r}0.00748 \pm \\
0.003 \\
\end{array}$ & $2.55 \pm 0.448$ & $1.78-3.63$ & 17.6 & 1010 \\
\hline \multirow{4}{*}{$\begin{array}{c}\text { Dry } \\
(56.5 \\
\mathrm{km})\end{array}$} & Adult & $2730 \pm 722.0$ & $\begin{array}{r}0.00847 \pm \\
0.0104\end{array}$ & $1.41 \pm 0.380$ & $0.83-2.50$ & 26.8 & 868 \\
\hline & $\begin{array}{l}\text { Sub- } \\
\text { adult* }\end{array}$ & $492.6 \pm 141.0$ & $\begin{array}{r}0.00935 \pm \\
0.0128 \\
\end{array}$ & $0.44 \pm 0.130$ & $0.24-0.79$ & 29.9 & 144 \\
\hline & Juvenile & $77.1 \pm 34.47$ & $\begin{array}{r}0.00812 \pm \\
0.0094 \\
\end{array}$ & $0.06 \pm 0.028$ & $0.02-0.15$ & 46.0 & 32 \\
\hline & Calf & $28.7 \pm 16.20$ & $\begin{array}{r}0.00845 \pm \\
0.0071\end{array}$ & $0.12 \pm 0.069$ & $0.04-0.37$ & 57.6 & 10 \\
\hline & Total & $3112 \pm 473.9$ & $\begin{array}{r}0.00856 \pm \\
0.0102 \\
\end{array}$ & $2.02 \pm 0.33$ & $1.45-2.81$ & 16.2 & 1456 \\
\hline
\end{tabular}

*- defecation rate from other seasons used to get the density estimate

\section{Figures}




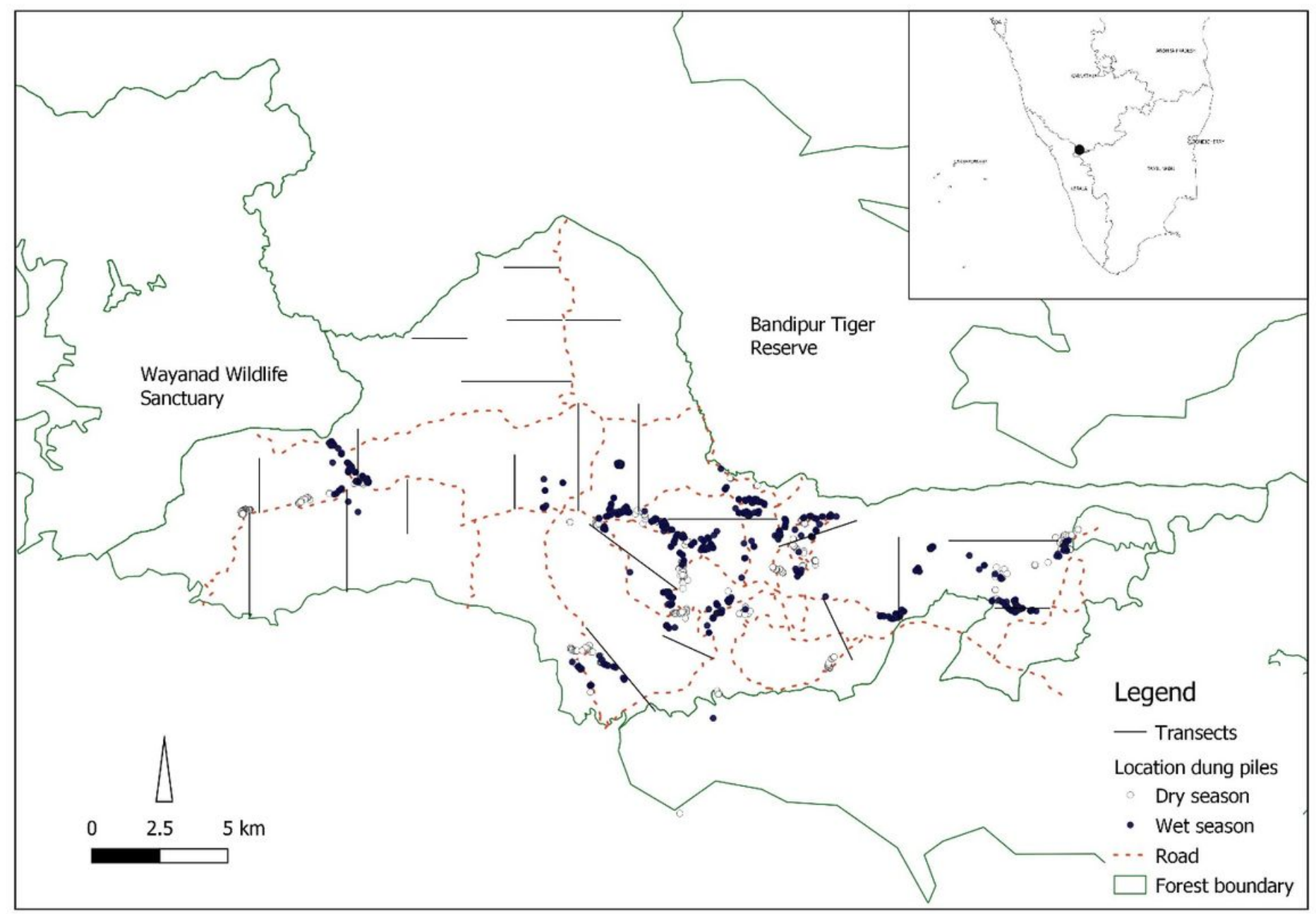

\section{Figure 1}

Map of study area location showing transect lines and dung piles marked in Mudumalai Tiger Reserve
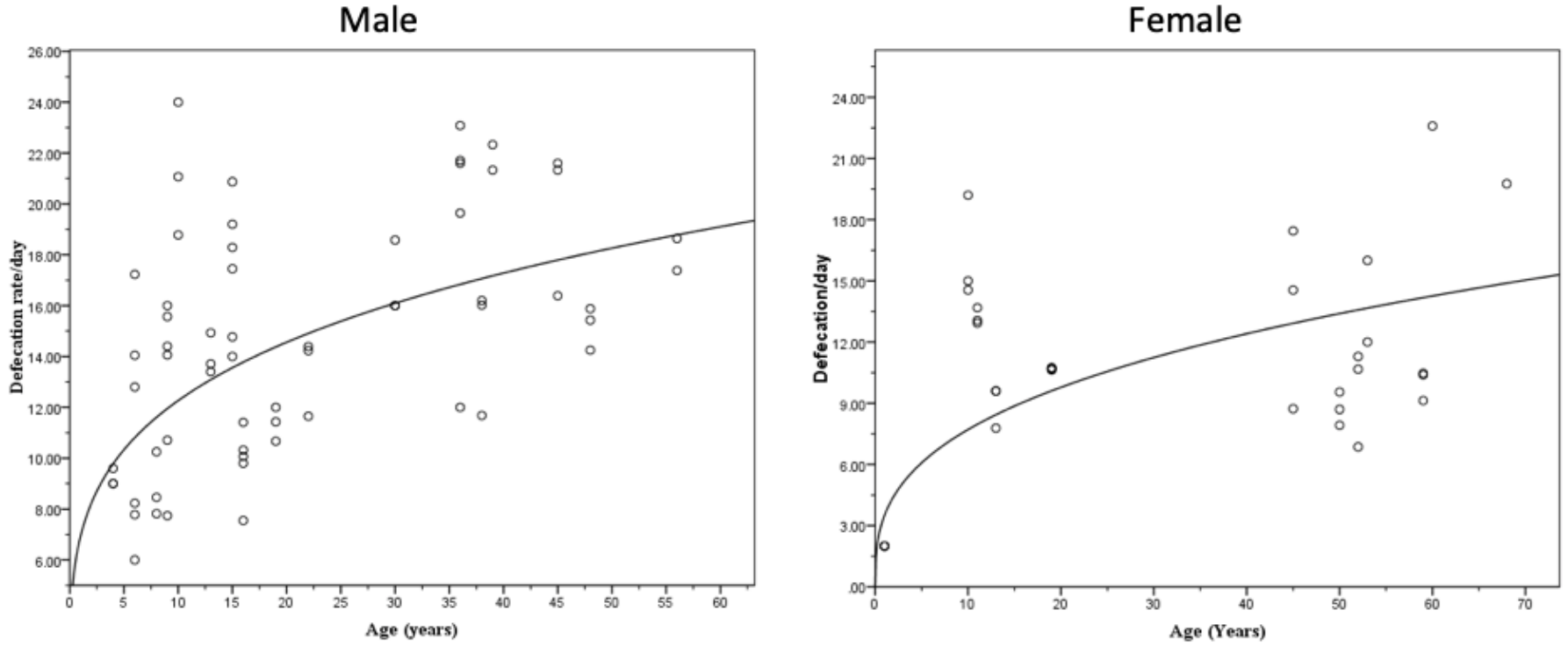
Figure 2

Power regression line of the relationship between the age of the animal and defecation rate for male and female elephants in Mudumalai Tiger Reserve

Male

$$
\operatorname{Linf}=49.39 \pm 1.02(47.76-51.82) ; \mathrm{t}_{0}=-2.62 \pm 1.99(-8.94-0.10) ; \mathrm{K}=0.12 \pm 0.026(0.07-0.17)
$$

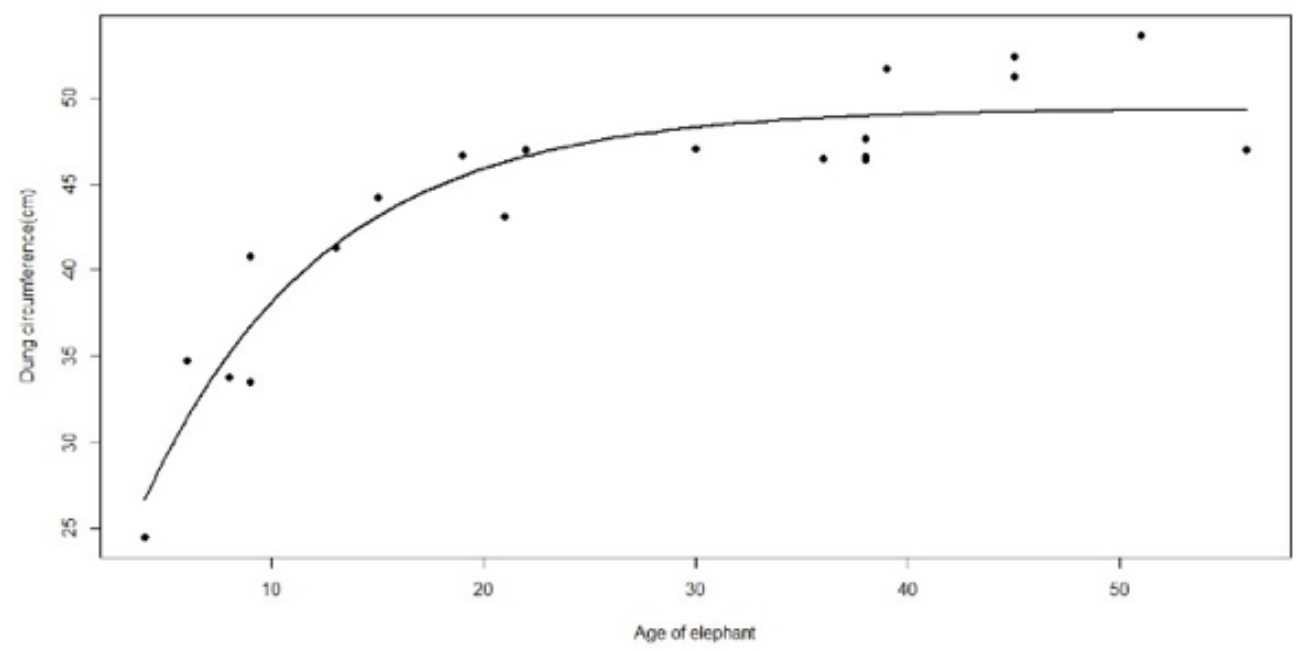

Female

$\operatorname{Linf}=42.87 \pm 2.24(39.8-49.32) ; \mathrm{t}_{0}=-5.68 \pm 5.22(-18.5-7.10) ; \mathrm{K}=0.10 \pm 0.06(0.03-0.32)$

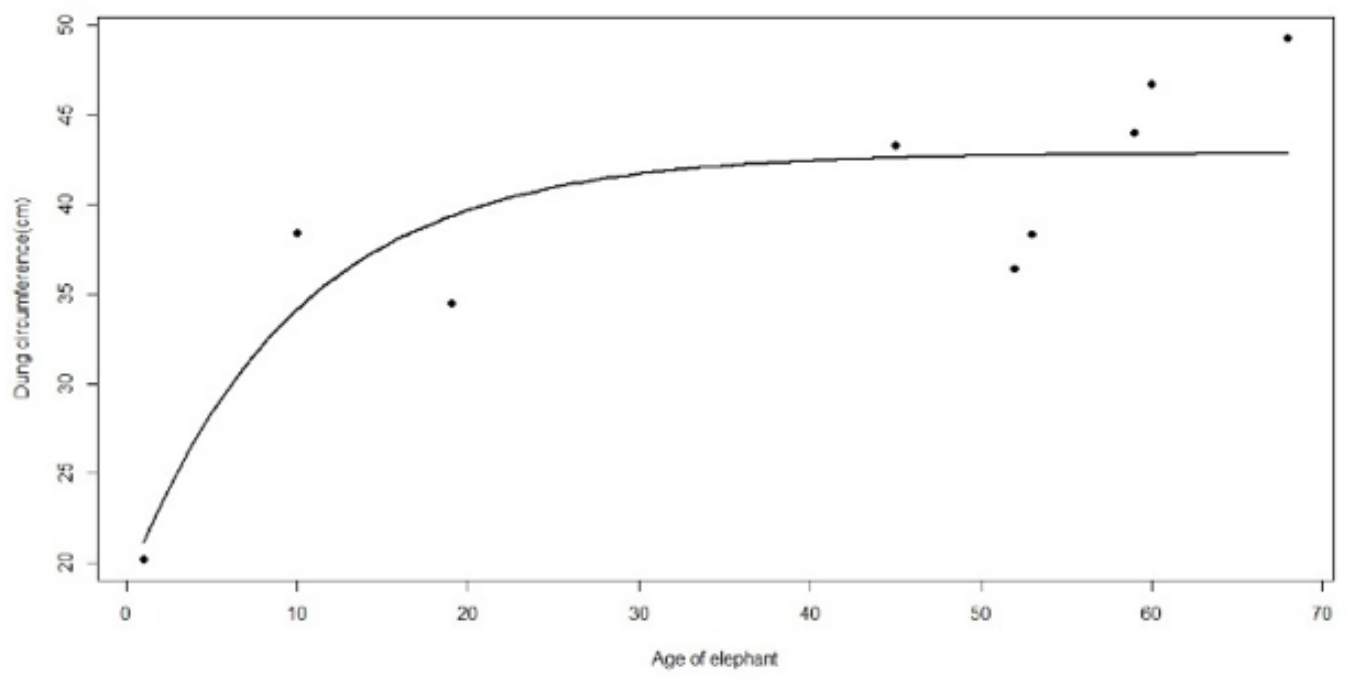

Figure 3

Growth parameters of the von Bertalanffy growth model based on dung circumference of dung boli produced by elephants of known and estimated age from Mudumalai Tiger Reserve. 


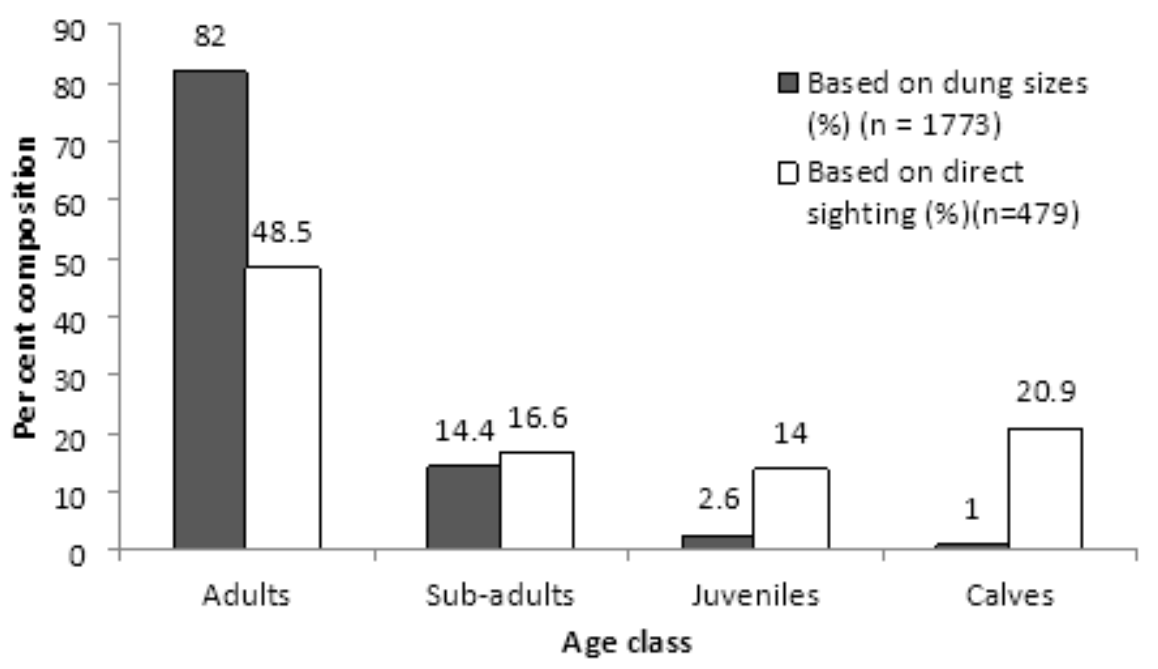

\section{Figure 4}

Age structure of elephant population estimated based on indirect dung size method and direct sighting method $\left(\chi^{\wedge} 2=6886 ; d f=4 ; p<0.00\right)$ 
a. Large

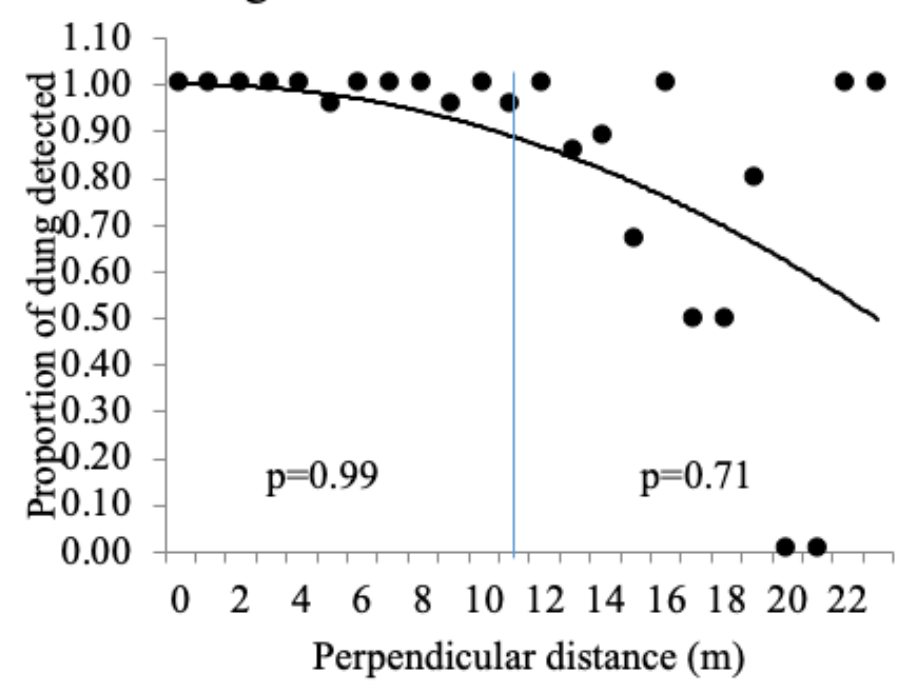

b. Medium

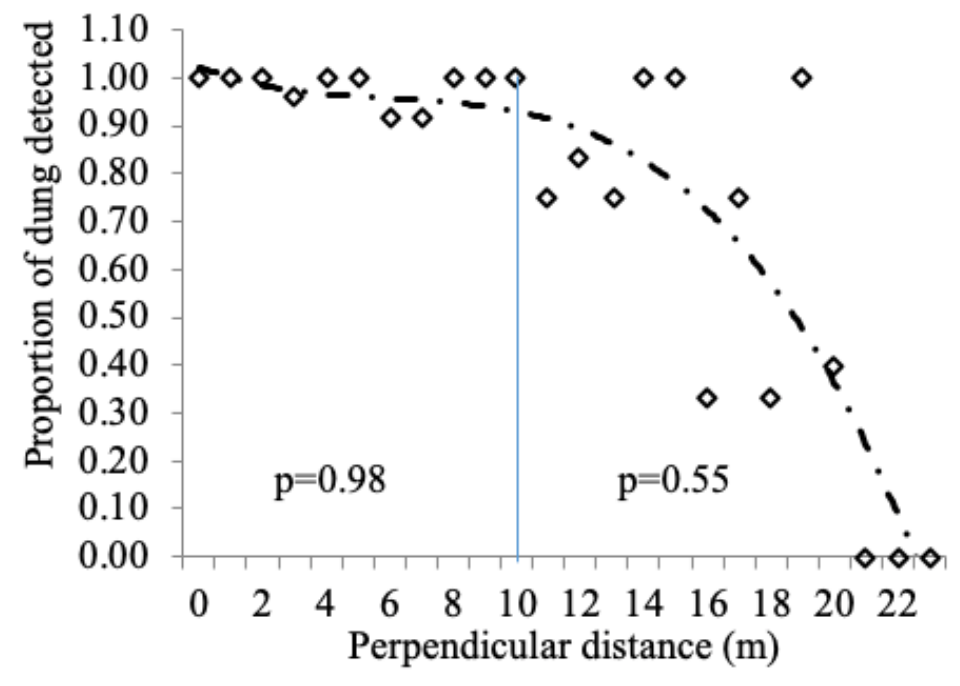

\section{c. Small}

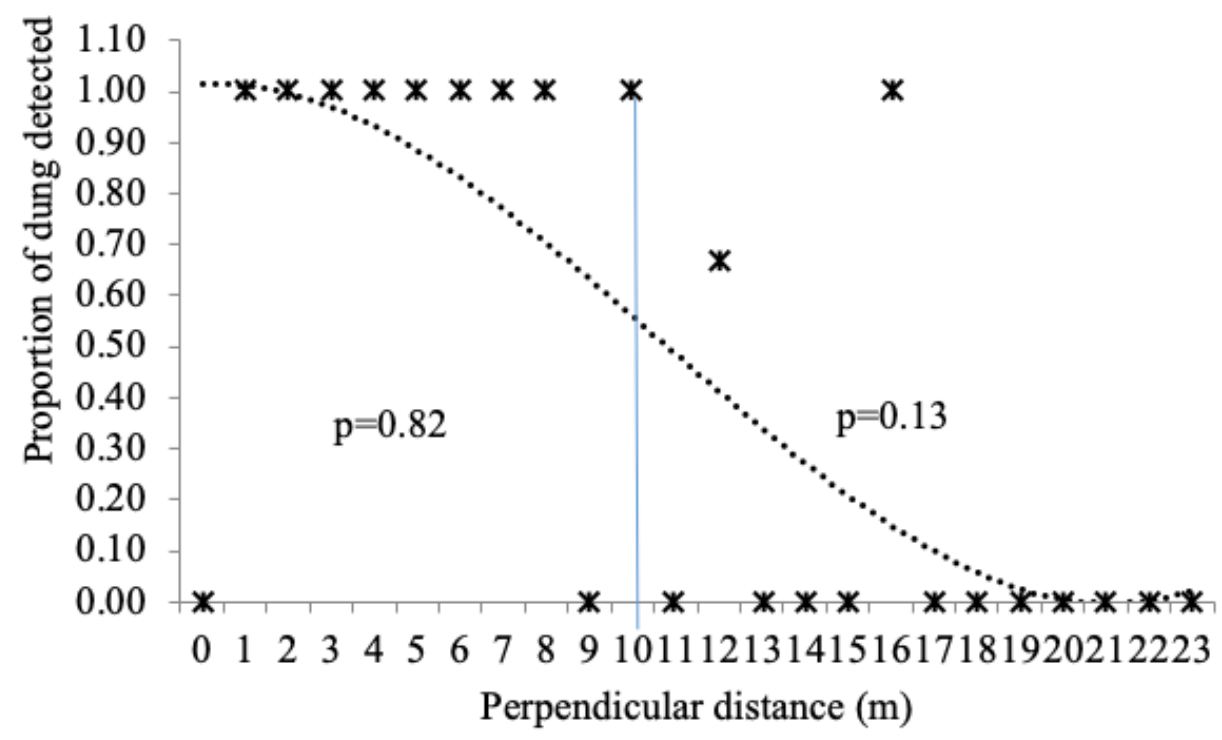

Figure 5

Proportion of dung piles detected of different size classes of dung piles at different perpendicular distance $(n=528)$. 
a. Adult $(n=347)$

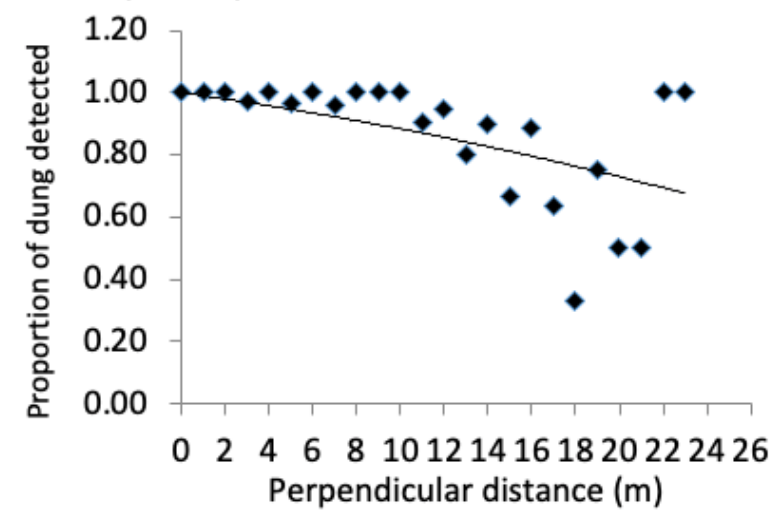

c. Juvenile $(n=39)$

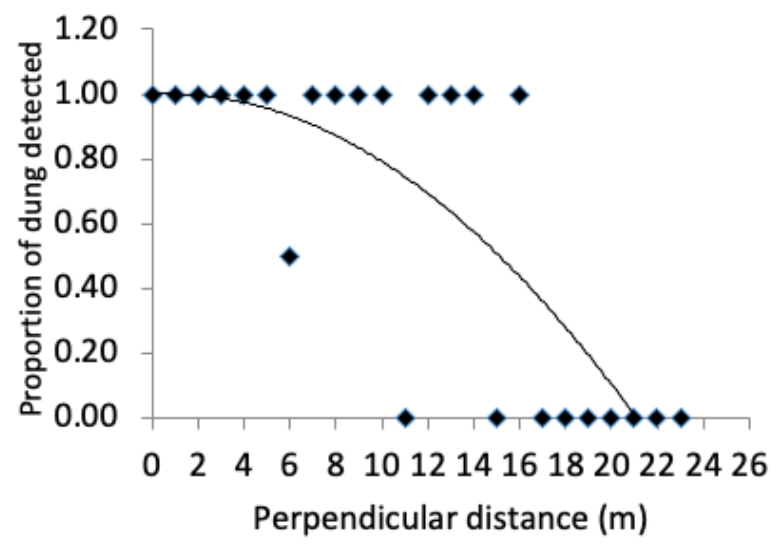

b. Sub-adult $(n=126)$

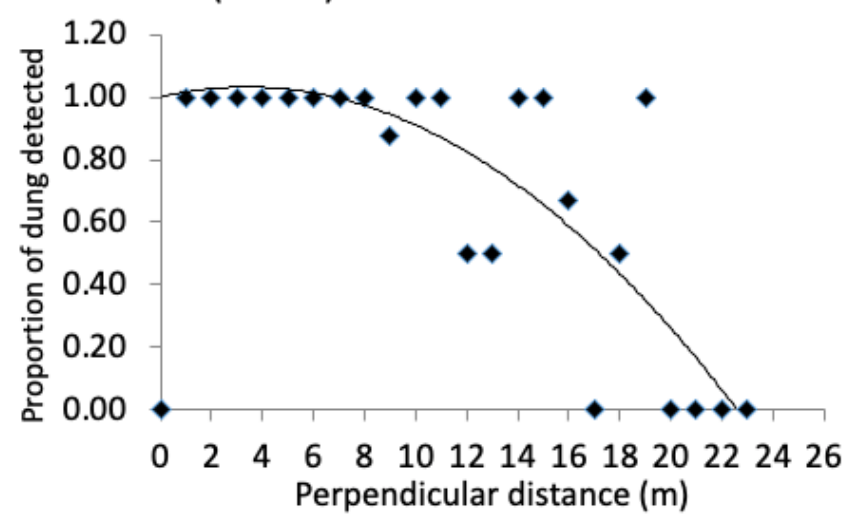

d. Calf $(n=16)$

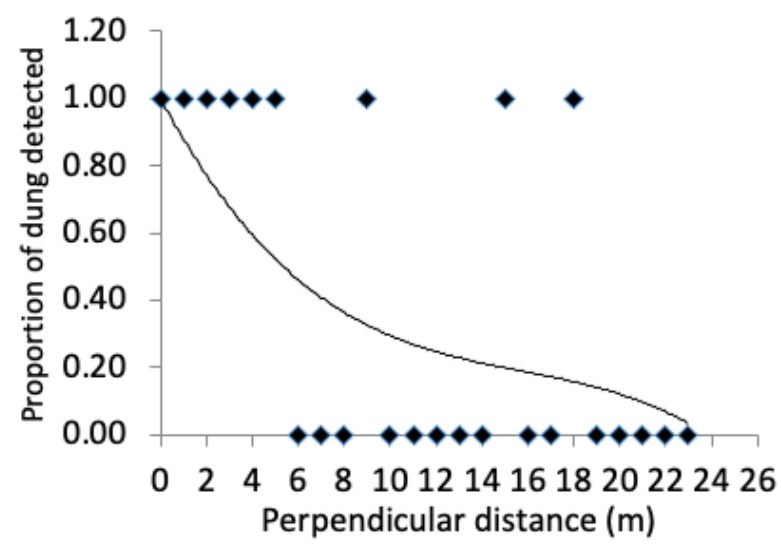

Figure 6

Proportion of dung detected of across age classes of elephant dung piles at different perpendicular distance $(n=528)$ 


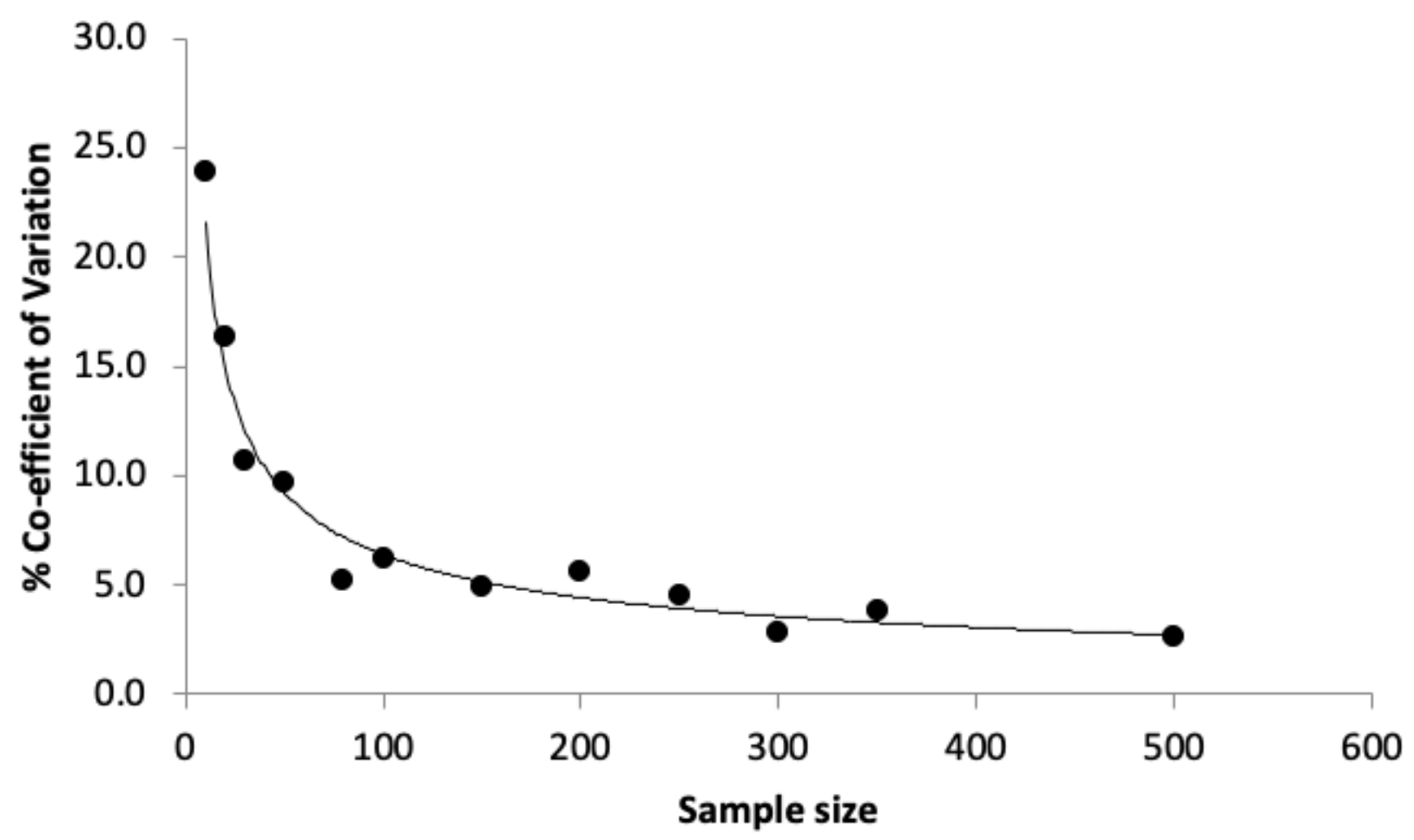

Figure 7

The influence of sample size on percent co-efficient of variation on dung decay rate estimated using random selection of dung data of dry season 